\title{
Tuberculosis in Brazil: New Cases, Healing and Abandonment in Relation to level of Education
}

Edwirde Luiz Silva Camêlo ${ }^{1}$, Dalila Camêlo Aguiar ${ }^{1}$, Rosiane Davina da Silva ${ }^{1}$, Tânia M. R. Monteiro de Figueiredo ${ }^{1}$, Andrés Gonzaléz Carmona ${ }^{2}$, Ramón Gutiérrez Sánchez ${ }^{2}$

\section{Abstract}

Setting: The situation of tuberculosis in Brazil, in each of its States and in the Federal District, with respect to patients' level of education.

Objective: To assess the strength of the relation between new cases of tuberculosis and treatment outcomes and rates of abandonment, with respect to the patients' level of education, in 2013.

Design: Transversal-quantitative study, using data from the Brazilian Disease and Notification Information System related to notified cases of tuberculosis, taking into account the patients' level of education. Data were analyzed by the hierarchical classification method (heat maps and dendrograms).

Results: In relation to numbers of new cases of tuberculosis and rates of healing and treatment abandonment, the lower the patients' level of education (less than 9 years' formal education), the higher the numbers of new cases of tuberculosis and the higher the rates of healing and treatment abandonment, throughout the country. Levels of schooling of 1-5 years and of 6-9 years are especially strongly related to a high incidence of treatment abandonment, in all the States. This nding was con rmed by clustering techniques. Treatment abandonment is especially prevalent in the States of São Paulo, Rio Grande do Sul and Rio de Janeiro, according to both analytic methods. In the States of Minas Gerais, Espírito Santo, Mato Grasso do Sul and Paraná, have the problem more similarly, but mixed with other groups of States.

Conclusion: Knowledge of the level of education of tuberculosis patients is of vital importance to health care managers, enabling them
1 Departamento de Estatística, Universidade Estadual da Paraíba.

2 Departamento de Estadística e Investigación Operativa. Universidad de Granada, Granada, España.

Contact information:

Edwirde Luiz Silva Camêlo.

”edwirde@uepb.edu.br 
to strengthen healthcare policies aimed at effective control of the disease. This study highlights the situation in Brazil with respect to different levels of education. Programmers to eradicate tuberculosis should focus particularly on those patients who have had fewer years of schooling and thus are more likely to suffer this disease. The population groups with education levels of 1-5 and 6-9 years presented high rates of treatment abandonment, in all States. Thus, the States of São Paulo, Rio Grande do Sul and Rio de Janeiro have the same problem for these levels of education, according to both techniques. In Minas Gerais, Espírito Santo, Mato Grasso do Sul and Paraná, the same problem is observed.

\section{Keywords}

Epidemiology, Medication Adherence, Treatment Refuse by the Patient, Tuberculosis.

\section{Introduction}

Tuberculosis (TB) is a common and life-threatening infectious disease which persists as a

major public health problem despite being curable and manageable [1, 2]. Around one third of the world's population is infected by Mycobacterium tuberculosis, which provokes 10 million new cases and 1-2 million deaths each year. Thus, TB is the second leading cause of death in the world by infectious disease, only exceeded by Acquired Immune Deficiency Syndrome [3].

In 2014, the WHO reported the occurrence of nine million new cases of TB in the world. In the same year, 76,000 cases were reported in Brazil, with an incidence of 37 per 100,000 inhabitants [5]. Brazil is sixteenth of the 22 countries that account for $80 \%$ of the worldwide occurrence of TB, and together with Russia, India, China and South Africa it accounts for $50 \%$ of all cases [3]. Apart from the epistemological situation of the disease, these countries have an important factor in common: they are all subject to the social determination of health and disease processes; in other words, social and healthcare inequalities are related [4].

TB is relatively neglected, and this fact contributes to the high prevalence of the disease among less economically privileged social classes $[2,6]$. Low le- vels of education favour the incidence of disease and hamperits control [7]. Accordingly, focusing on education is a question of major importance in the eld of health care and disease prevention. If levels of education can be raised, the vulnerability of the population to TB will be reduced $[8,9]$.

To enhance the control of TB, which is considered to be one of the seven main diseases a effecting the population [1, 10], the Brazilian Health Ministry has included TB in its National Agenda for Research Priorities in Health.

In view of the importance of obtaining detailed information about the characteristics of TB patients, in this study we analyze the strength of the relation between three TB parameters (new cases, rates of healing and rates of treatment abandonment) and the level of education among the Brazilian population in 2013. Previous works were not specific indicate cases of abandonment, new case and death from TB en relation to specific school levels.

\section{Method}

A transversal-quantitative study was performed, using data from the Brazilian Disease Notification Information System (DNIS), available at the Health Ministry website [5]. 
The study population was composed of all notified cases of TB in 2013, in the 26 Brazilian States and the Federal District, a total of 91.576 cases. The sample analysed was composed of the 68.606 cases for which the individuals' level of education was known to the DNIS, classified as follows: illiterate, (1-5) years, (6-9) years, (10-12) years, university studies (UGI) and university graduates (UG). The following sample variables were recorded: New cases $(53,816)$, Treatment success $(52.377)$ and Treatment abandonment (9.673).

The study data were compiled in March 2015, and stored and analyzed using the statistical program R, version 3.2.0 [11].

The elements from the sample of cases were clustered by variables and distributed into categories, based on their similarity, using a hierarchical classifying method (dendrogram) and a heat map. Distances between the States and the level of education were defined by the nearest neighbour method and the average Euclidean distance.

In the clustering approach, the distance matrix is usually determined by initially taking each object as a group, or cluster. The individuals within a cluster are similar on some level of education, while the cluster are dissimilar from one another.

A heat map is a graphical representation of data whereby the individual values contained in a matrix are represented as colours or as shades of grey; each approach has perceptual advantages and disadvantages [12].

The heatmap function of the NeatMap package can be used to obtain heat maps and dendrograms. Our data are represented with the level of education at the top of the heat map and the States on the left hand side [13]. The dendrogram shows the stages of group formation, looking like an inverted tree.

A correlation matrix derived from the data is shown as a false colour, with levels of grey encoding the correlation. The heat map contains diffe- rent shades, indicating the intensity of the relation or the values of the variables, ranging from white (strongest relation or highest value), through light grey to dark grey (weakest relation or lowest values).

\section{Silhouette Coefficient}

The silhouette coefficient is a measure of cohesion and of the separation of clusters. It is based on the difference between the average distance to points in the closest cluster and to points in the same cluster. For each point $x_{i}$ we calculate its silhouette coefficient $s_{i}$ as [24].

$$
s_{i}=\frac{\mu_{\min }^{\text {out }}\left(x_{i}\right)-\mu_{\text {in }}\left(x_{i}\right)}{\max \left\{\mu_{\min }^{\text {out }}\left(x_{i}\right), \mu_{\text {in }}\left(x_{i}\right)\right\}}
$$

where $\mu_{i n}\left(x_{i}\right)$ is the mean distance from $x_{i}$ to points in its own cluster $\hat{y}_{i}$

$$
\mu_{i n}\left(x_{i}\right)=\frac{\sum x_{j} \in C_{\hat{y}_{i, j \neq i}} \delta\left(x_{i}, x_{j}\right)}{n_{\hat{y}_{i}}-1}
$$

and $\mu_{\text {min }}^{\text {out }}\left(x_{i}\right)$ is the mean of the distances from $x_{i}$ to points in the closest cluster:

$$
\mu_{i n}\left(x_{i}\right)=\min _{j \neq \hat{y}_{i}}\left\{\frac{C_{y \in C_{j}} \delta\left(x_{i}, y\right)}{2}\right\}
$$

\section{Rand Index and y Rand Index Adjusted}

The Rand index (or measure) and the adjusted Rand index are used as objective criteria for the evaluation of clustering methods [25]. These indices measure the level of compatibility between a given partition and a benchmark partition for the same data. The quantities of interest are then defined as follows:

$$
I R=\frac{a+b}{a+b+c+d}
$$

The Rand index can be considered a measure of the percentage of correct decisions made by the 
algorithm. In other words, the more homogeneous or heterogeneous the groups, the more the index will vary from $0 \leq I R \leq 1$.

This study was approved by the research ethics committee of the Universidade Estadual da Paraíba (UEPB) (Register $N^{\circ}$ 45954315.5.0000.5187), in accordance with Resolution 466/2012 of the National Health Council, the regulatory body for research with human beings in Brazil.

\section{Results}

The results obtained suggest that throughout Brazil persons with a university-level education have a minimal impact on the numbers of new TB cases. On the other hand, those with the least formal education (nine years or less) are the most vulnerable to the desease (Figure 1).

Figure 1: New cases of tuberculosis versus level of education, Brazil, 2013.

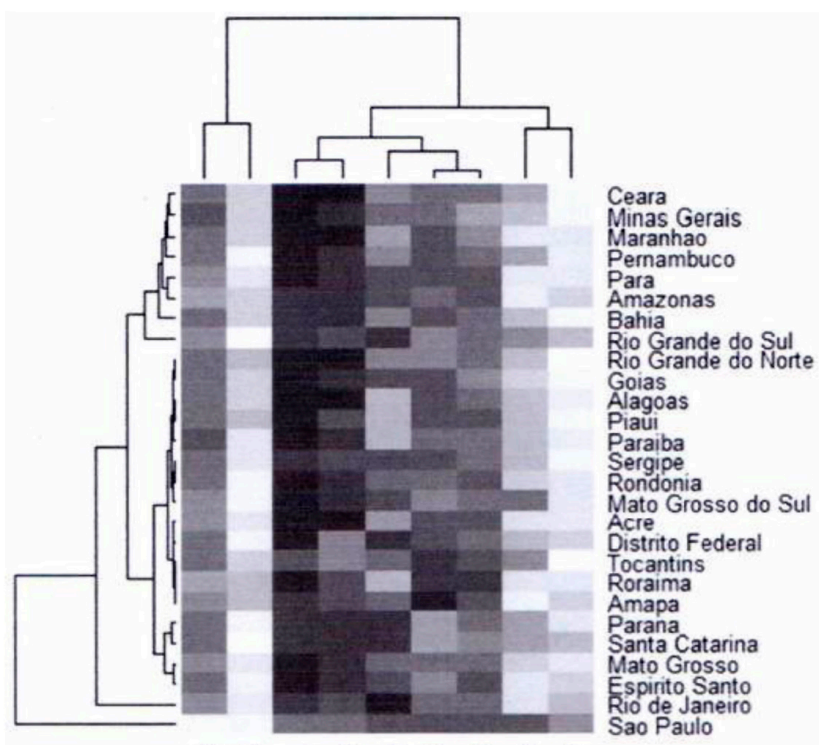

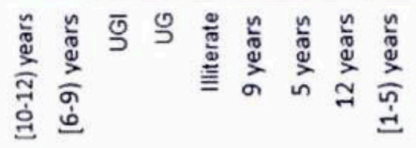

New cases of TB in the States of Santa Catarina and Rio Grande do Sul are strongly related to the 6-9 years level of education among the study population. In São Paulo, on the other hand, most new cases took place among patients with 6-12 years of education. In Amazonas, Amapá, Roraima and Rio de Janeiro, new cases were most strongly related with patients who had had 12 years of education (Figure 1).

The States of Alagoas, Rio Grande do Norte, Piauí and Paraíba, especially the last two, contained the highest proportions of patients classified as Illiterate (Figure 1). All of these States are in north-eastern Brazil.

The left side of the dendrogram in Figure 1 shows that some States form clusters with a similar average Euclidean distance, that is, the same relation between levels of education and rates of new cases. One such cluster is formed by Minas Gerais, Maranhão, Amazonas, Santa Catarina, Mato Grosso and Paraná. Another is formed by Piauí and Roraima. In São Paulo, almost all types of relation are present, while at the second-lowest level, Rio de Janeiro contains three large groups. (Table 1)

Table 1. Groups formed by rates of TB treatment abandonment, for all education levels.

\begin{tabular}{|c|l|}
\hline Groups & \multicolumn{1}{c|}{ States } \\
\hline 1 & São Paulo \\
\hline 2 & Rio Grande do Sul and Rio de Janeiro \\
\hline 3 & Pernambuco, Ceará, Pará and Bahia \\
\hline 4 & From Piauí to Alagoas \\
\hline 5 & From Paraíba until Paraná \\
\hline
\end{tabular}

At the top of the dendrogram in Figure 1, levels of new cases are similar in the groups with 6-9 and 10-12 years of education. These groups are separated from the others by a considerable margin, after which the groups with 1-5 years and 12 years of education present the same pattern. The groups with 5 and 9 years of education form another group, while those classed as Illiterate are close to the UG and UGI groups.

Another dendrogram was constructed, using the same States and variables, with the same levels of education, but with respect to cases in which the 
treatment resulted in a cure. In our study sample, $73,3 \%$ of TB patients were cured. The heat map shows that the highest rates of cure correspond to the following levels of education: 1-5 years, 6-9 years and 12 years. The strongest relations between rates of cure and level of education were recorded in Tocantins and Rio Grande do Norte for patients with 1-5 years of education, and in Santa Catarina and Rio Grande do Sul for those with 6-9 years.

The top part of the dendrogram, corresponding to the level of education, shows that the cluster formed by patients with 6-9 and 10-12 years of education is considerably separated from the other clusters, with respect to new cases of TB.

In the heatmap, the intensity of the colours reflects the quantity of cases. It can be seen that there are lower levels of new cases among the UG, UGI and Illiterate groups, where rates of cure are also lower.

The population classed as Illiterate in the States of Alagoas, Piauí, Sergipe, Paraíba, Roraima and Acre presented a higher rate of treatment success.

The level of treatment abandonment was 14\% overall. The groups with 1-9 years of education presented the same patterns of behaviour for new cases and treatment success.

The highest rates of treatment abandonment were recorded for the population groups with 1-9 years of education. The left side of the dendrogram contains a small cluster formed by Ceará, Pará, Bahia and Piauí, together with two large clusters formed by São Paulo, Rio de Janeiro and Rio Grande do Sul with the other State, which all present similar rates of treatment abandonment.

In contrast to the other States, particularly high rates of treatment abandonment were recorded for patients with 6-9 years of education in Espirito Santo, Acre, Santa Catarina and Rio Grande do Sul. The Federal District had the highest proportion of patients with 5 years of education.

In Acre, patients with 1-5 and 10-12 years of education presented low rates of treatment abandon- ment. However, the rate among patients with 6-9 years was significantly higher.

In Amapá, Piauí, Paraíba and Alagoas, the group classed as Illiterate presented the highest rate of treatment abandonment.

In São Paulo, the clusters of patients with 6-9and 10-12 years of education had the highest levels of treatment abandonment in the State.

On the left side of Figure 2, a line separates the patient groups and the States. It can be seen that there are ve groups with common characteristics regarding the level of education. These groups are listed in Table 1.

Figure 2: Treatment abandonment and rates of healing versus level of education, Brazil, 2013.

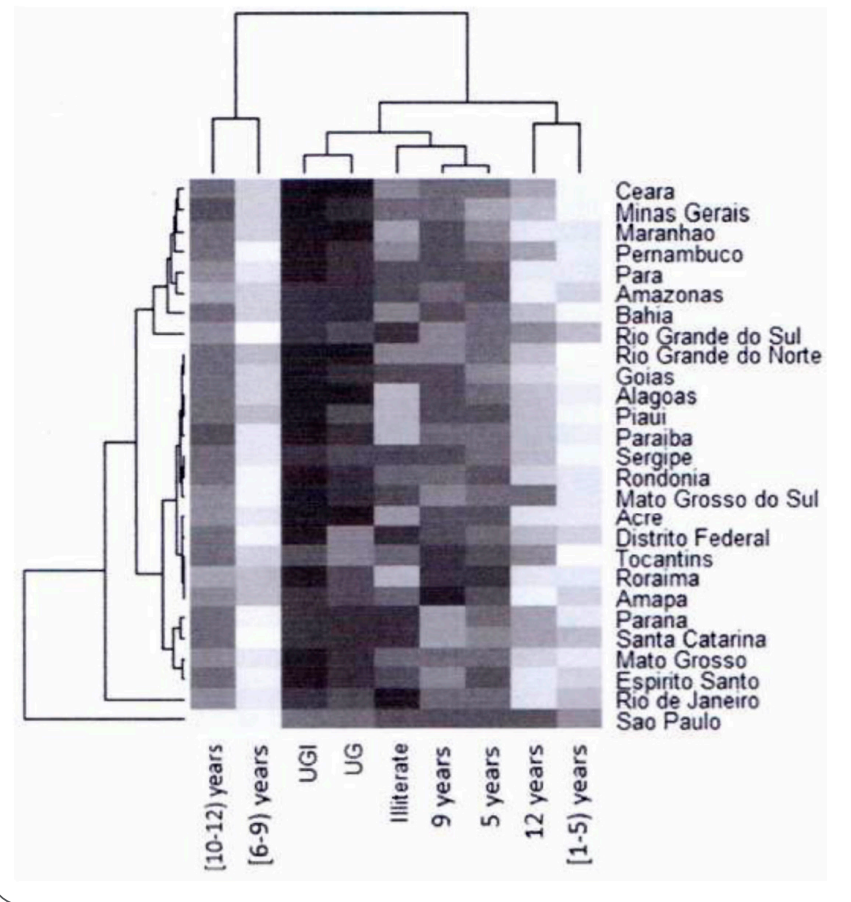

To clarify the information for the relation between the States and the 6-9 year and 10-12 year levels of education, which are very heterogeneous, we constructed a new cluster, using the nearest single neighbour method, together with the group average clustering method (Figure 3 ). The group average method produces a small group of States (Espírito Santo, Pará, Mato Grosso and Santa 
Catarina), compared with the nearest neighbour method.

In the States of Amapá, Piauí, Paraíba and Alagoas, the groups of Illiterate patients are responsible for the highest levels of treatment abandonment. In São Paulo, however, these correspond to the patients with 6-9 and 10-12 years of education.

Analysis of Figure 2 shows that patients with 1-5 and 6-9 years of education present a high rate of treatment abandonment, in all the States. The question then arises: which groups of States in Brazil face this problem to a similar degree, for patients with the same level of education? Figure 3 shows that the nearest neighbour clustering technique and that of the non-weighted arithmetic average present some similarity. This confirms the existence of the problem among the States where these levels of education are prevalent. Thus, the States of São Paulo, Rio Grande do Sul and Rio de Janeiro have the same problem for these levels of education, according to both techniques. In Minas Gerais, Espírito Santo, Mato Grasso do Sul and
Paraná, the same problem is observed, but mixed with other groups of States. In this search for a structure from which clusters could be derived, no outliers were detected.

Regarding the relation between level of education and treatment abandonment, Table 2.

Table 2. Index values and coefficients for treatment abandonment and levels of education.

\begin{tabular}{l|c|c|} 
& Number of groups & Value \\
\hline $\begin{array}{l}\text { Mean Silhouette } \\
\text { statistic }\end{array}$ & 5 & 0.36 \\
\hline Index of Rand & $4-5$ & 0.86 \\
\hline $\begin{array}{l}\text { Index of Rand Adjusted } \\
\text { Cophenetic coefficient }\end{array}$ & $4-5$ & 0.63 \\
\hline
\end{tabular}

The Rand statistic, which is symmetric, measures the proportion of point pairs, A perfect clustering has a Rand value of 1 , The value of the Rand and adjusted Rand statistic for five groups was 0.77, in each case, The mean Silhouette statistic for five groups was 0.38 (Figure 4), The cophenetic coefficient was 0.92 .

Figure 3: Comparison of single (left) and average (right) rates of treatment abandonment, in all States, for patients with 1-5and 6-9 years of education.

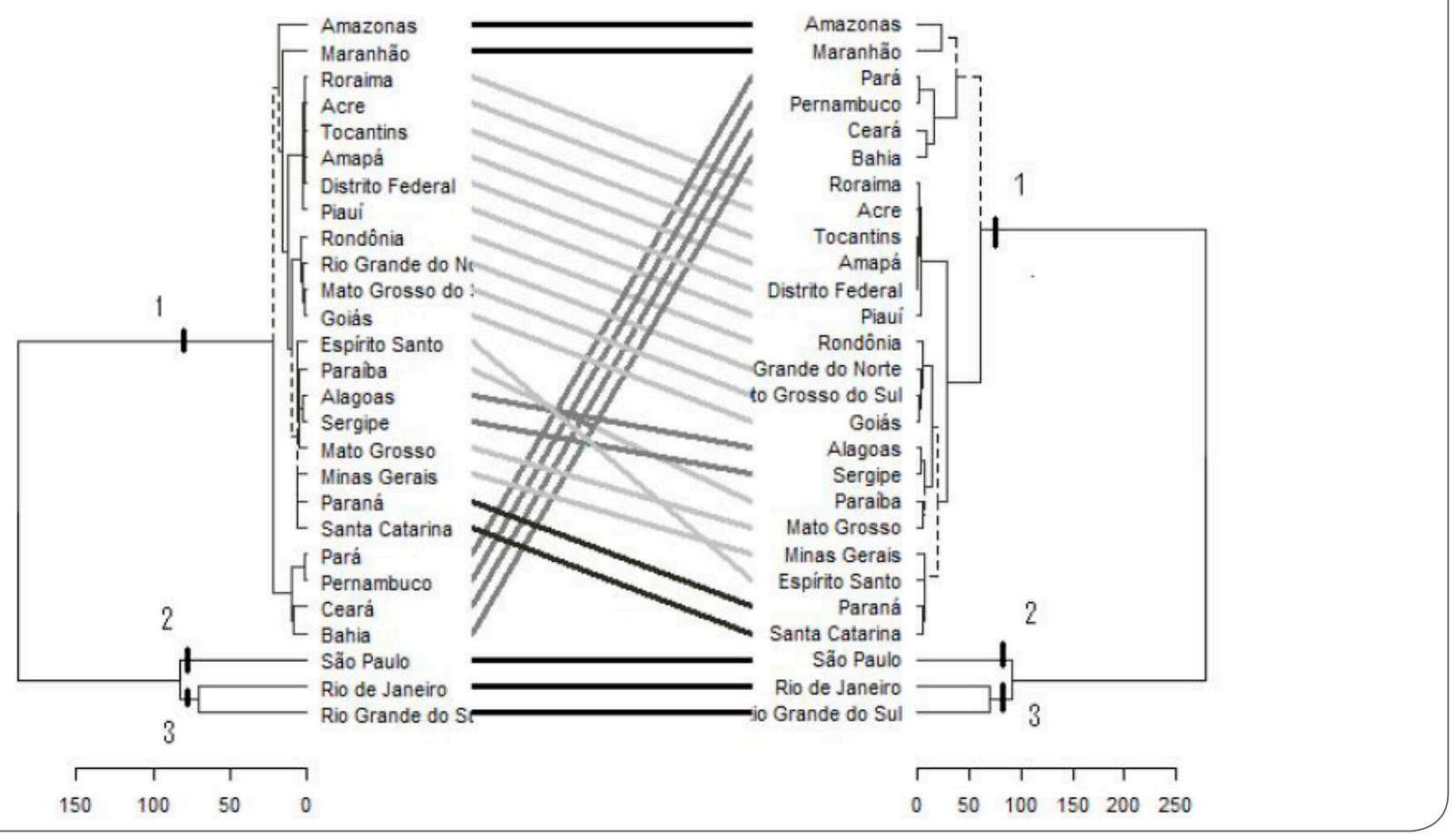


Figure 4: Rand index, Adjusted Rand index and Silhouette coefficient (All levels of education).

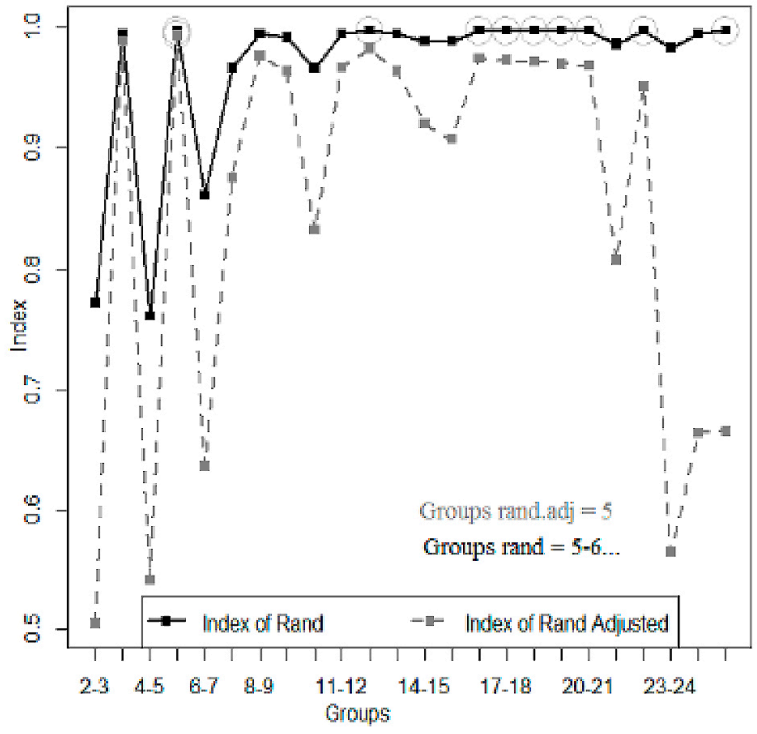

Table 3 shows the mean Silhouette statistic and the cophenetic coefficient for treatment abandonment with respect to education levels of 1-5 and 6-9 years (Figure 3).

Table 3. Coeffcients for treatment abandonment with respect to education levels of 1-5 and 6-9 years.

\begin{tabular}{|l|c|c|}
\hline & Number of groups & Value \\
\hline $\begin{array}{l}\text { Mean Silhouette } \\
\text { statistic }\end{array}$ & 3 & 0.85 \\
\hline Cophenetic coefficient & 3 & 0.97 \\
\hline
\end{tabular}

The results obtained after cluster analysis, considering the single and average methods, are shown in Figure 3, There are differences between the groups, as the fusion of group 1 with groups 2 and 3 takes place at very high levels of the scale, above 250 for the average method.

The groups have widely-varying numbers of elements, ranging from two for group 1 to 24 States in group 2, to the three States of São Paulo, Rio de Janeiro and Rio Grande de Sul in Group 3. Both techniques show that groups 2 and 3 present the same problem with respect to levels of education. The States ranging from Roraima to Santa Catarina

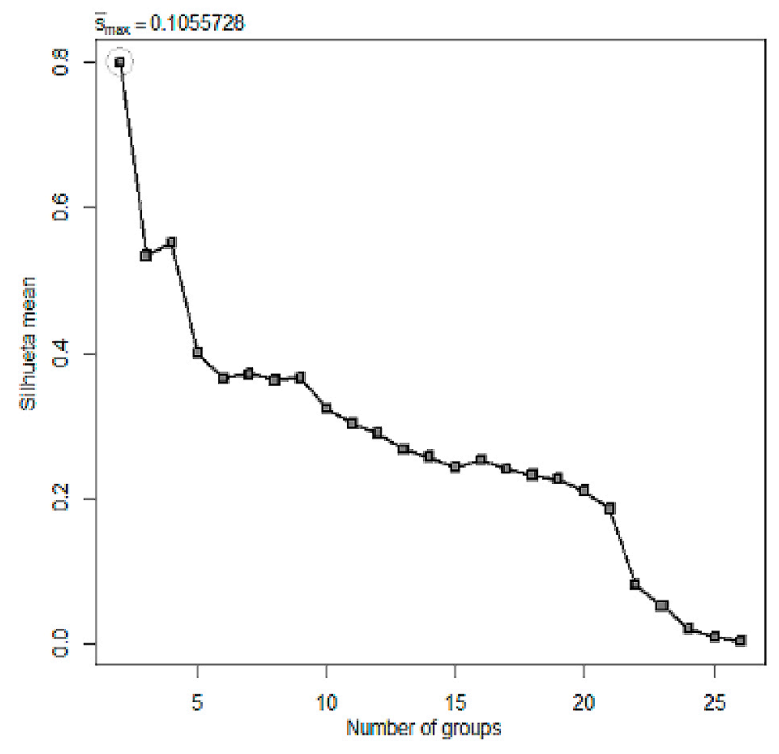

have almost the same degree of problem at these levels.

\section{Discussion}

This study shows that patients with 1-9 years of education are more likely to have TB. Moreover, they present higher levels of new cases, healing and treatment abandonment. Similar findings have been reported by studies conducted in Ghana, Vietnam and the Dominican Republic [14].

In its 2010 census, the Brazilian Institute of Geography and Statistics reported that $9.6 \%$ of the population was classed as illiterate, and that the northeastern part of the country accounted for $53.3 \%$ of this population (7,43 million), Nevertheless, the incidence of illiteracy is believed to have fallen in recent years [15].

Taking into account the level of education as a social and economic variable, the generally low level of education in Brazil revealed by this study reflects an important social factor of individual and social vulnerability to TB, which contributes to the persistence of the disease and is strongly linked to the social determination of the disease process $[7,16]$. Indeed, its prevalence is concentrated in countries 
with intense social inequalities, as is the case in Brazil $[13,17]$.

Various studies have obtained comparable results with respect to new cases of $T B$, healing and treatment abandonment in all the States of Brazilian, over several years [17, 1, 19, 20]. However, unlike the present study, none of them analyzed the relation between the number of TB cases and the patients' level of education or demonstrated the occurrence of cases in Brazilian states.

Our results show that in the immediate future Brazil will fail to meet the WHO goals for increasing rates of healing and for reducing those of treatment abandonment. This is worrying, because this situation suggests the disease will continue to spread, that more strains resistant to medicine will appear and that treatment costs and mortality rates will continue to rise $[1,20]$.

In this context, the patients' level of education is an important empowerment tool; it facilitates their understanding of health information and generates the means to strengthen individual autonomy and selfcare regarding health and disease prevention [22].

According to Paulo Freire (1996) [23], education is a process of ceaseless organization, by which people are encouraged to construct a choosing process focused on their own interests. Thus, teaching is not a mere transfer of knowledge, but a process that creates possibilities for creation and production.

[...] though they are different, who forms, forms himself and reforms when forming; and who is formed, forms himself and forms to be formed. In this sense teaching is not the transfer of knowledge, subjects, or form, but the action of giving form, style and soul to an undecided and accommodated body (FREIRE, 1996, p, 23) [23].

Further study of health care necessities is necessary; many such needs are related to social production and reproduction and access to health actions [21],

\section{Conclusion}

It is of great importance to determine the level of education of TB patients and the distribution of education levels throughout the country, because this is one of the major factors determining the quality of healthcare attention obtained by individuals with TB. Our study shows that patients with a low level of education (less than 9 years) are more likely to suffer TB and to abandon treatment for this disease. Moreover, the WHO goals for healthcare in this field are far from being met in Brazil.

The States where the relation between new cases of $\mathrm{TB}$ and limited education were strongest were Rio Grande do Sul and Santa Catarina (6-9 years of education) and Tocantins (1-5 years of education). The strongest relations between healing and limited education were recorded in the same States plus Rio Grande do Norte (6-9 years of education). The highest rates of treatment abandonment were recorded in Rio Grande do Sul, Acre, Santa Catarina and Espírito Santo for patients with 6-9 years of education and in the Federal District for those with 5 years of education.

The population groups with education levels of 1-5 and 6-9 years presented high rates of treatment abandonment, in all States. Nearest-neighbour and non-weighted average distance clustering techniques con rm the severe problem faced in this respect in the States of São Paulo, Rio Grande do Sul and Rio de Janeiro,

As the patients' level of education is clearly very relevant to the healthcare problem examined in this study, we conclude that political authorities must consider strategies to increase the population's access to education and to make public investments in actions in this field, in association with healthcare managers and other personnel, in order to empower the population and to achieve a better control of the disease. Accordingly, programmes aimed at improving healthcare attention to reduce the impact of TB in Brazil should take into account the importance of levels of education in this respect. 


\section{References}

1. Brasil, Manual de recomendações do para o controle da tuberculose no Brasil. Ministerio da Saude, Bras lia - Distrito Federal, 2011

2. Ruffino-Netto A; Nogueira JA. Desempenho da atenção basica no controle da tu-berculose. Rev, Saude Publica, 2009, 43 (5): 825-831, 2009.

3. World Health Organization (WHO). Global tuberculosis control: surveillance, planning, financing, Geneva: WHO, 2014.

4. Bertolozzi mr, Takahashi RF, Hino P, Litvoc M, Franca Fos. O controle da tuberculose: um desafio para a saúde pública. RevMed, 2014, 93 (2): 83-9

5. BRASIL, Ministerio da Saúde. Sistema de Informação de Agravos de Noticação, Tuberculose: casos confirmados diagnosticados, 2014. Disponível em: http://dtr2004,saude,gov,br/sinanweb/. Acesso em: 13 de marco de 2015.

6. Monroe AA, Cardoso-Gonzales Ri, Palha PF, et al, Envolvimento de equipes da atenção básica a saúde no controle da tuberculose. Rev, Esc, Enferm, USP, 2008, 42 (2): 262-67.

7. Figueiredo TMRM, Acesso ao tratamento de tuberculose: avaliação das características organizacionais e de desempenho dos serviços de saúde. Ribeirão Preto. Universidade de São Paulo, 2008

8. Ayres JR, C, M; Calazans G, J; Saletti Filho H, C, Franca J, R, I. Risco, vulnerabilidade e práticas de prevenção e promoção da saúde. In: Campos G, Minayo MCS, Akerman M, Drumond Jr M, Carvalho YM, organizadores, Tratado de Saúde Coletiva, São Paulo: Editora Fiocruz: 2006, 375-417.

9. Ekwueme OC, Omotowo B, Agwuna KK. Trengthening contact tracing capacity of pulmonary tuberculosis patients in Enugu, southeast Nigeria: a targeted and focused health education intervention study. BMC Public Health, 2014, 14: 1175.

10. BRASIL, Agenda Nacional de Prioridades de Pesquisa em Saúde. Ministério da Saúde, Brasília - Distrito Federal, 2008.

11. $R$ Development Core Team (2011). R: A Language and Environment for Statistical Computing, Vienna, Austria : the R Foundation for Statistical Computing, ISBN: 3-900051-07-0, Available online at http://www, R-project,org/.

12. Borland, David; Taylor, Russell (2007). "Rainbow Color Map (Still) Considered Harmful". IEEE Computer Graphics and Applications 27 (2): 14

13. Rajaram SY, Oono Y, Package "Neatmap". R: A Language and Environment for Statistical Computing. R Foundation for Statistical Computing, 2012, Vienna, Austria.

14. Mauch V, Bonsu F, Gyapong M, et al. Free tuberculosis diagnosis and treatment are not enough: patient cost evidence from three continents. Int J Tuberc Lung Dis, 2013, 17 (3): 381-387.

15. Instituto Brasileiro de Geografia e Estatística - IBGE. Disponível em: http://www,ibge,gov,br/home/. Acesso em 18 de março, 2015

16. Bertolozzi MR. A adesão ao tratamento da tuberculose na perspectiva da estratégia do tratamento diretamente supervisionado (DOTS) no Município de São Paulo [tese livredocência]. São Paulo: Escola de Enfermagem - Universidade de São Paulo; 2005.
17. Silva PF, Silva GM, Mendes CAJ. Fatores associados ao abandono do tratamento da tuberculose pulmonar no Maranhão, Brasil, no período de 2001-2010. Cad, Saude Publica, 2014; 30

18. Campani STA, Moreira JS, Tietbohe CN. Fatores preditores para o abandono do tratamento da tuberculose pulmonar preconizado pelo Ministério da Saúde do Brasil na cidade de Porto Alegre (RS). J. Bras. Pneumol, 2011; 37 (6): 776-2.

19. Vasconcelos FCS, Chatkin MN. Perfil Epidemiologico da Tuberculose em Pelotas - Rio Grande do Sul, Brasil. Rev. Bras. Ciên. Saude, 2008, 12 (3): 229-238.

20. Coelho DMM, Viana RL, Madeira CA, Ferreira LOC, Campelo V. Perfil epidemiológico da tuberculose no Município de TeresinaPI, no período de 1999 a 2005. Epidemiol. Serv. Saude, 2012, 19 (1) $34-43$

21. Wingfield T, Boccia D, Tovar $M$, et al. Defining Catastrophic Costs and Comparing Their Importance for Adverse Tuberculosis Outcome with Multi-Drug Resistance: A Prospective Cohort Study, Peru. PLoS Medicine, 2014, 11 (7), E1001675.

22. Hino P, Bertolozzi MR, Takahasshi RF, Egry EY. Necessidades em saúde segundo percepções de pessoas com tuberculose pulmonar. Rev. Esc. Enferm, USP, 2012, 46 (6):1438-45, São Paulo.

23. Freire, Paulo. Pedagogia da autonomia: saberes necessários a prática educativa, 29 ed, São Paulo: Paz e Terra, 1996.

24. Mohammed J, Zaki, Wagner Meira JR, Data Mining and Analysis. Fundamental Concepts and Algorithms. Cambridge University Press, 2014.

25. Rand, W, M. "Objective criteria for the evaluation of clustering methods". Journal of the American Statistical Association (American Statistical Association) 66 (336): 846 - 850, 1971. 